\title{
Nano-fertilizers: A Novel Way for Enhancing Nutrient Use Efficiency and Crop Productivity
}

\author{
A. Qureshi $i^{1 *}$, D.K. Singh ${ }^{2}$ and S. Dwivedi ${ }^{3}$ \\ ${ }^{1}$ Department of Agronomy, College of Agriculture and Research Station, Kanker, Indira \\ Gandhi Krishi Vishwavidyalaya, Chhattisgarh-494334, India \\ ${ }^{2}$ Department of Agronomy, G.B. Pant University of Agriculture and Technology, \\ Pantnagar-263145, Uttarakhand, India \\ ${ }^{3}$ Department of Agronomy, College of Agriculture, Indira Gandhi Krishi Vishwavidyalaya, \\ Raipur, Chhattisgarh-492001, India \\ *Corresponding author
}

\section{A B S T R A C T}

Nano fertilizers are the important tools in agriculture to improve crop growth, yield and quality parameters with increase nutrient use efficiency, reduce wastage of fertilizers and cost of cultivation. Nano-fertilizers are very effective for precise nutrient management in precision agriculture with matching the crop growth stage for nutrient and may provide nutrient

\section{Keywords}

Nanotechnology, Nanoporous zeolites, Nutrients use efficiency, Smart fertilizer

\section{Article Info}

Accepted: 26 January 2018 Available Online: 10 February 2018 throughout the crop growth period. Nano-fertilizers increase crop growth up to optimum concentrations further increase in concentration may inhibit the crop growth due to the toxicity of nutrient. Nano-fertilizers provide more surface area for different metabolic reactions in the plant which increase rate of photosynthesis and produce more dry matter and yield of the crop. It is also prevent plant from different biotic and abiotic stress. Because of the limitation in arable lands and water resources, the development of agriculture sector is only possible by increasing of resources use efficiency with the minimum damage to production bed through effective use of modern technologies. Among these, nanotechnology has the potential to revolutionize the agricultural systems, biomedicine, environmental engineering, safety and security, water resources, energy conversion, and numerous other areas. Nanostructured formulation through mechanisms such as targeted delivery or slow/controlled release mechanisms and conditional release, could release their active ingredients in responding to environmental triggers and biological demands more precisely. Studies show that the use of nano-fertilizers causes an increase in nutrients use efficiency, reduces soil toxicity, minimizes the potential negative effects associated with over dosage and reduces the frequency of the application. Hence, nanotechnology has a high potential for achieving sustainable agriculture, especially in developing countries.

\section{Introduction}

The First Green Revolution during 1970s targeted to the four basic elements of production system viz. semi-dwarf high yielding varieties of rice and wheat, extensive use of irrigation, fertilizers and agro-chemicals and consequently resulted in terrific increase in the agricultural production. However, the agricultural production is experiencing a 
plateau nowadays, which has adversely affected the livelihood base of the farming community at large. In fact, the country is in need of a Second Green Revolution. Nanoscale science and nanotechnologies are envisioned to have the potential to revolutionize agriculture and food systems.

The term "Nanotechnology" was first defined in 1974 by Norio Taniguchi of the Tokyo Science University. Nanotechnology, abbreviated to "Nanotech", is the study of manipulating matter on an atomic and molecular scale. By and large nanotechnology deals with structures in the size range between 1 to $100 \mathrm{~nm}$ and involves developing materials or devices within that size.

At the nano-scale the matter presents altered properties which are novel and very different from those observed at macroscopic level. The change in properties is due to the reduced molecular size and also because of changed interactions between molecules. The properties and possibilities of nanotechnology, which have great interest in agricultural revolution, are high reactivity, enhanced bioavailability and bioactivity, adherence effects and surface effects of nanoparticles (Gutierrez et al., 2011). Customized manufactured products are made from atoms; their properties depend on how those atoms are arranged.

World agricultural cropping systems intensively using large amount of fertilizers, pesticides, herbicides to achieve more production per unit area but using more doses than optimum of these chemicals and fertilizers leads to several problems like environment pollution (soil, water, air pollution), low input use efficiency, decrease quality of food material, develop resistance in different weeds, diseases, insects, less income from the production, soil degradation, deficiency of micro nutrient in soil, toxicity to different beneficial living organism present above and below the soil surface etc. Despite these problems there is also challenge to feed the growing population of the world $[1,2]$. Therefore in the future, there is need to produce nutritive agricultural produce rich in protein and other essential nutrient required to the human and animal consumption that is why emphasis should be laid on production of high quality food with the required level of nutrients and proteins $[1,3]$. For solving these problems in crop production nano-fertilizers, pesticides and herbicides may effective tools in agriculture for better pest and nutrient management because these nano-materials having more penetration capacity, surface area and use efficiency which avoid residues in environment. Size below $100 \mathrm{~nm}$ nanoparticles can use as fertilizer for efficient nutrient management which are more ecofriendly and reduce environment pollution. Hence, these agricultural useable nano-particle develop with the help of nanotechnology can be exploited in the value chain of entire agriculture production system [4].

\section{Challenges and solutions of present agricultural practices}

Present agriculture is generally chemically intensive where using more doses of chemicals for insect, disease, weeds and nutrient management to get maximum production per unit area without caring about natural resources and ecosystems.

In present agriculture fertilizer contributes to the tune of $50 \%$ of the agricultural production but increasing use higher doses of fertilizers does not guarantee to improved crop yield but it leads several problems like degradation of soil and pollution of surface and underground water resources. Solution: Increase the fertilizer nutrient use efficiency and reduce doses. According to [5], reported that fertilizer alone contributed $50 \%$ in crop production. 
High transportation cost of fertilizers due to require in large quantity. Solution: Decrease the application rate of fertilizers. More wastes of fertilizers material by using over doses in crop production. Solution: Value-addition to traditional fertilizers and reduce doses per unit area. Multi nutrient deficiency in the soils. Solution: combine application of macro and micronutrient sources.

\section{Nano-scale}

\section{What are nanoparticles?}

A nanoparticle (or nanopowder or nanocluster or nanocrystal) is a small particle with at least one dimension less than $100 \mathrm{~nm}$.

\section{Nanometer $=10^{-9} \mathrm{~m}=1$ billionth of a meter}

For comparison, a virus is roughly 100 nano metres $(\mathrm{nm})$ in size.

A key point- People have been exposed to nanoparticles for as long as there have been people; in other words, "nano" isn't inherently bad

It's hard to imagine just how small nanotechnology is. One nanometer is a billionth of a meter, or $10^{-9}$ of a meter. Here are a few illustrative examples:

There are 25,400,000 nanometers in an inch

A sheet of newspaper is about 100,000 nanometers thick

On a comparative scale, if a marble were a nanometer, then one meter would be the size of the Earth

\section{Properties of nano-particle}

Large proportion of surface atoms - Smaller particles allow better coverage of surface area
Nano sized particles can even pass through the cell wall in plants and animals.

Nanotechnologists use this process to deliver at cellular level which is more effective than the conventional method.

High surface energy

Spatial confinement

\section{Nano-fertilizers (Smart nutrient delivery system)}

Nano-fertilizers "Nano fertilizers are synthesized or modified form of traditional fertilizers, fertilizers bulk materials or extracted from different vegetative or reproductive parts of the plant by different chemical, physical, mechanical or biological methods with the help of nanotechnology used to improve soil fertility, productivity and quality of agricultural produces. Nanoparticles can made from fully bulk materials.

At nano scale physical and chemical properties are differ than bulk material. Rock phosphate if use as nano form it may increase availability of phosphorus to the plant because direct application of rock phosphate nano particles on the crop may prevent fixation in the soil similarly there is no silicic acid, iron and calcium for fixation of the phosphorus hence, it increase phosphorus availability to the crop plants.

\section{Need of nano-fertilizers}

Indian agriculture feels the pain of fatigue of green revolution. In the past 50 years, the fertilizer consumption exponentially increased from 0.5 (1960's) to 24 million tonnes (2013) that commensurate with four-fold increase in food grain output (254 million tonnes).

Despite the resounding success in grain growth, it has been observed that yields of 
many crops have begun to stagnate as a consequence of imbalanced fertilization and decline in organic matter content of soils.

The optimal NPK fertilizer ratio of $4: 2: 1$ is ideal for crop productivity while the current ratio is being maintained at 10: 2.7: 1 in India.

Nitrogenous fertilizers, particularly urea are heavily subsidized by the government and thus its application is more obvious than other nutrients.

The fertilizer response ratio in the irrigated areas of the country has decreased from 13.4 $\mathrm{kg}$ grain / kg nutrient applied in 1970's to just $3.7 \mathrm{~kg}$ in 2005 .

In other words, more amounts of fertilizers is required to produce the same quantity of grain output. For instance, $27 \mathrm{~kg}$ NPK/ ha was required to produce one tonne of grain in 1970 while the same level of production can be achieved by $109 \mathrm{~kg}$ NPK/ha in 2008 .

In order to achieve a target of 300 million tonnes of food rains and to feed the burgeoning population of 1.4 billion in 2025 , the country will require 45 million tonnes of nutrients as against a current consumption level of 23 million tonnes.

The extent of multi-nutrient deficiencies are alarmingly increasing year by year which is closely associated with a crop loss of nearly 25-30\%.

The extent of nutrient deficiencies in the country is in the order of 89, 80, 50, 41, 49 and $33 \%$ for $\mathrm{N}, \mathrm{P}, \mathrm{K}, \mathrm{S}, \mathrm{Zn}$ and $\mathrm{B}$, respectively.

In fact, the country is in need of a Second Green Revolution. Nano fertilizers are envisioned to have the potential to revolutionize agriculture.
Mode of nutrient delivery in nanofertilizers

\section{Nanotechnology applications in agriculture}

Now a days nanotechnology providing different nano devices and nano material which having a unique role in agriculture such as nano biosensors to detect moisture content and nutrient status in the soil and also applicable for site specific water and nutrient management, Nano-fertilizers for efficient nutrient management, Nano-herbicides for selective weed control in crop field, Nanonutrient particles to increase seed vigor, Nanopesticides for efficient pest management. alginate/ chitosan nano-particles can be use as herbicide carrier material specially for herbicide such as paraquat [6]. Nano herbicides are effective in weed management [7]. Hence, nanotechnology have greater role in crop production with environmental safety, ecological sustainability and economic stability. The nano-particles produced with the help of nanotechnology can be exploited in the value chain of entire agriculture production system [8].

\section{Application and use of Nanofertilizer}

Nano-fertilizers "Nano fertilizers are synthesized or modified form of traditional fertilizers, fertilizers bulk materials or extracted from different vegetative or reproductive parts of the plant by different chemical, physical, mechanical or biological methods with the help of nanotechnology used to improve soil fertility, productivity and quality of agricultural produces. Nanoparticles can made from fully bulk materials [9].

At nano scale physical and chemical properties are differ than bulk material. Similarly reported [10]. Rock phosphate if use as nano form it may increase availability of phosphorus to the plant because direct 
application of rock phosphate nano particles on the crop may prevent fixation in the soil similarly there is no silicic acid, iron and calcium for fixation of the phosphorus hence it increase phosphorus availability to the crop plants[11].

\section{Advantages of nanofertilizers}

Nanofertilizer facilitate higher nutrient use efficiency

The nano-fertilizers have higher surface area it is mainly due to very less size of particles which provide more site to facilitate different metabolic process in the plant system result production of more photosynthets.

Due to higher surface area and very less size they have high reactivity with other compound. They have high solubility in different solvent such as water. Particles size of nano-fertilizers is less than $100 \mathrm{~nm}$ which facilitates more penetration of nano particles in to the plant from applied surface such as soil or leaves.

Nano fertilizer have large surface area and particle size less than the pore size of root and leaves of the plant which can increase penetration into the plant from applied surface and improve uptake and nutrient use efficiency of the nano-fertilizer. Reduction of particle size results in increased specific surface area and number of particles per unit area of a fertilizer that provide more opportunity to contact of nano-fertilizers which leads to more penetration and uptake of the nutrient [12].

Fertilizers encapsulated in nano-particles will increase availability and uptake of nutrient to the crop plants [13]. Zeolite based nanofertilizers are capable to release nutrient slowly to the crop plant which increase availability of nutrient to the crop though out the growth period which prevent loss of nutrient from denitrification, volatilization, leaching and fixation in the soil especially NO3-N and NH4-N. Particle size below 100 $\mathrm{nm}$ nano-particles can use as fertilizer for efficient nutrient management which are more eco-friendly and reduce environment pollution [4]. Main reason for high interest in fertilizers is mainly their penetration capacity, size and very higher surface area which is usually differ from the same material found in bulk form. This is partially due to the fact that nano particles show a very high surface: volume ratio. Thus, the reactive surface area is proportionally over-represented in nano particles compared to larger particles. Particle surface area increases with decreasing particle size and the surface free energy of the particle is a function of its size. Similar result obtained [12].

\section{Nutritional value and health}

Nano fertilizers providing greater role in crop production and several research study revealed that nano fertilizers enhanced growth, yield and quality parameters of the crop which result better yield and quality food product for human and animal consumption.

This translates into an improvement to three major areas of production.

\section{Yields}

Several research studies revealed that application of nano-fertilizers significantly increase crop yield over control or without application of nano-fertilzer it is mainly because of increasing growth of plant parts and metabolic process such as photosynthesis leads to higher photosynthets accumulation and translocation to the economic parts of the plant. Foliar application of nano particles as fertilizer significantly increases in yield of the crop [14]. 
Table.1 Size of different organisms and biomolecules on the micro- and nanometric scale

\begin{tabular}{|l|l|l|l|}
\hline No. & \multicolumn{1}{|c|}{$\begin{array}{c}\text { Nature of organisms and different } \\
\text { biosubjects }\end{array}$} & \multicolumn{1}{|c|}{$\begin{array}{c}\text { Size range } \\
(\mu \mathrm{m})\end{array}$} & \multicolumn{1}{|c|}{$\begin{array}{c}\text { Size on nanometric } \\
\text { scale }(\mathrm{nm})\end{array}$} \\
\hline $\mathbf{1}$ & Plant, animal cell & $10-100$ & $10000-100000$ \\
\hline 2 & Bacteria & $\leq 1-10$ & $\leq 1000-100$ \\
\hline 3 & Virus & $0.03-0.1$ & $30-100$ \\
\hline 4 & Simple molecules (proteins, DNA turns) & $0.001-0.01$ & $1-10$ \\
\hline 5 & Atoms (DNA 'base') & $0.0001-0.001$ & $0.1-1$ \\
\hline
\end{tabular}

Table.2 Emerging multi-nutrient deficiencies in soils

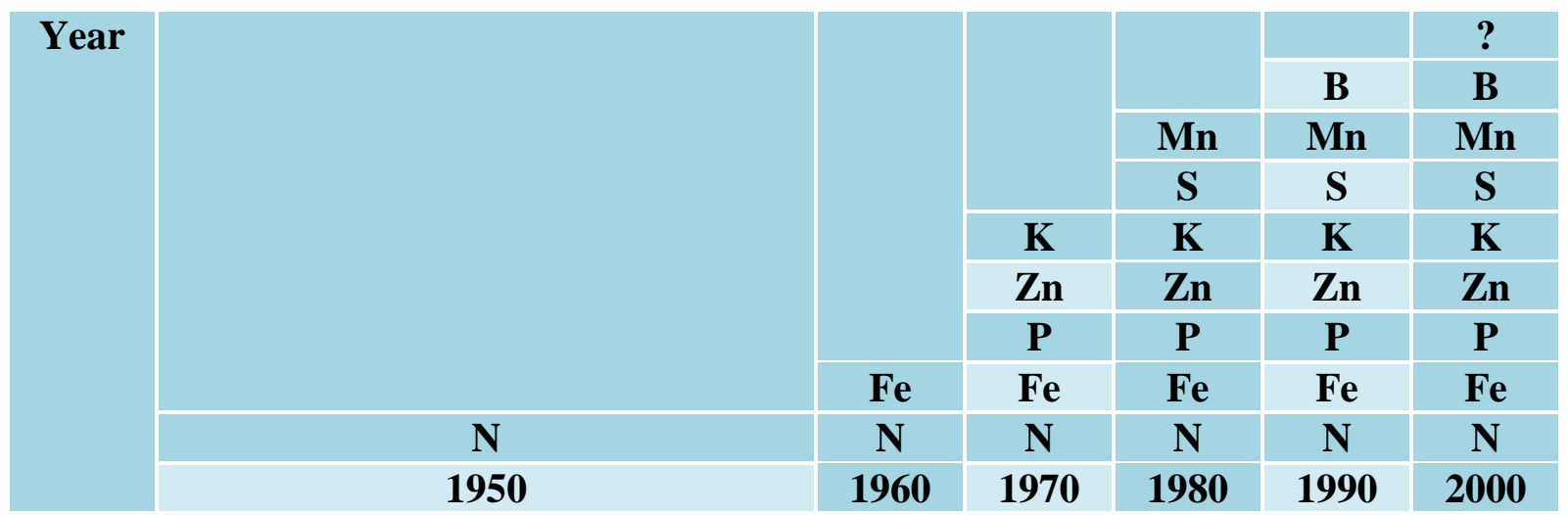

Table.3 Some of advantages related to transformed formulation of conventional fertilizers using Nanotechnology (Cui et al., 2006)

\begin{tabular}{|c|c|}
\hline Desirable Properties & Examples of Nanofertilizers-Enabled Technologies \\
\hline Controlled release formulation & $\begin{array}{l}\text { So-called smart fertilizers might become reality through } \\
\text { transformed formulation of conventional products using } \\
\text { nanotechnology. The nanostructured formulation might } \\
\text { permit fertilizer intelligently control the release speed } \\
\text { of nutrients to match the uptake pattern of crop. }\end{array}$ \\
\hline $\begin{array}{l}\text { Solubility and dispersion for mineral } \\
\text { micronutrients }\end{array}$ & $\begin{array}{l}\text { Nanosized formulation of mineral micronutrients may } \\
\text { improve solubility and dispersion of insoluble nutrients } \\
\text { in soil, reduce soil absorption and fixation and increase } \\
\text { the bio-availability. }\end{array}$ \\
\hline Nutrient uptake efficiency & $\begin{array}{l}\text { Nanostructured formulation might increase fertilizer } \\
\text { efficiency and uptake ratio of the soil nutrients in crop } \\
\text { production, and save fertilizer resource. }\end{array}$ \\
\hline Controlled release modes & $\begin{array}{l}\text { Both release rate and release pattern of nutrients for } \\
\text { water-soluble fertilizers might be precisely controlled } \\
\text { through encapsulation in envelope forms of semi- } \\
\text { permeable membranes coated by resin-polymer, waxes } \\
\text { and sulphur. }\end{array}$ \\
\hline Effective duration of nutrient release & $\begin{array}{l}\text { Nanostructured formulation can extend effective } \\
\text { duration of nutrient supply of fertilizers into soil. }\end{array}$ \\
\hline Loss rate of fertilizer nutrients & $\begin{array}{l}\text { Nanostructured formulation can reduce loss rate of } \\
\text { fertilizer nutrients into soil by leaching and/or leaking. }\end{array}$ \\
\hline
\end{tabular}




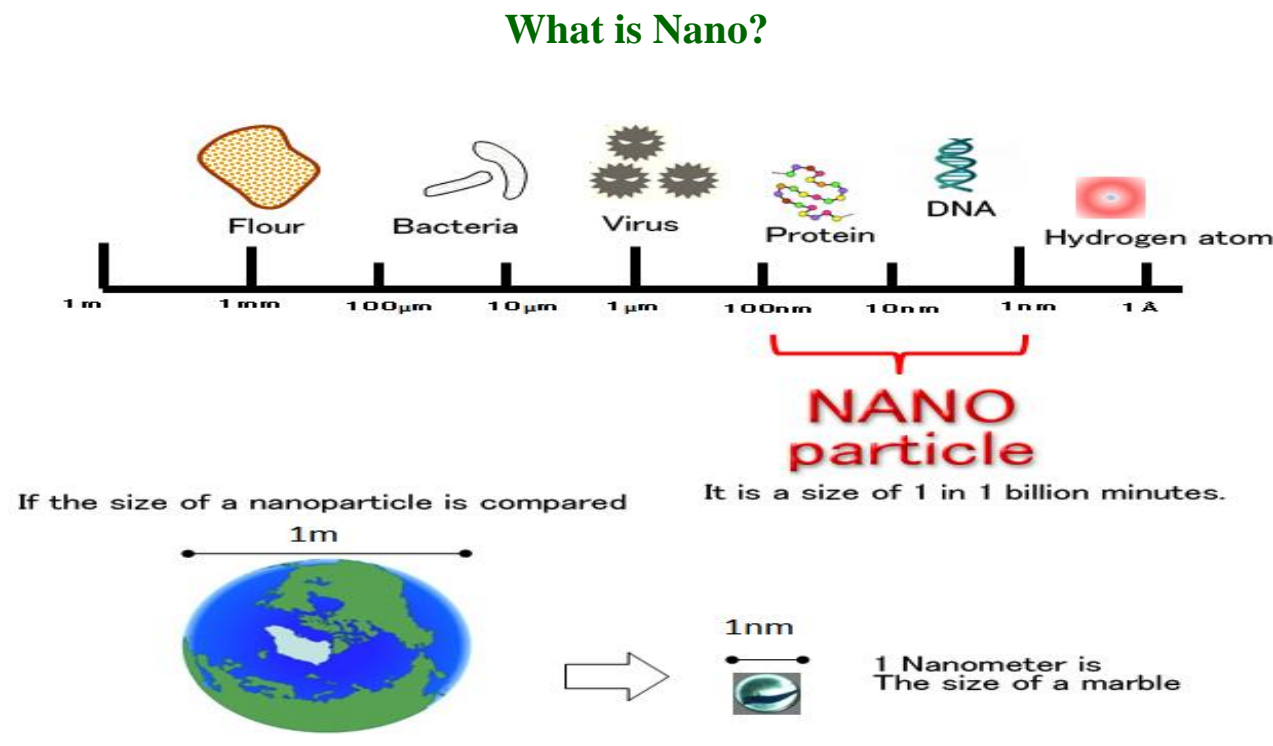

The diameter of the earth is $1 \mathrm{~m}$.

Coated with a thin nano material layer - Nutrient encapsulation by nano micro coating

- Slow release fertilizer/agrochemicals based on Nanotechnology

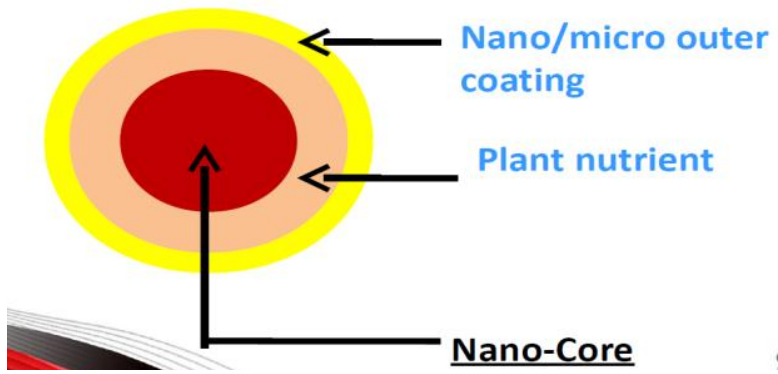

Delivered as particles nano-scale dimensions $\mathrm{Eg}$. $\mathrm{ZnO}, \mathrm{CuO}, \mathrm{TiO} 2$

Nutrient can be encapsulated inside nanomaterials such as nanotubes nanoporous materials such as Nanotubes, Nanoporous materials

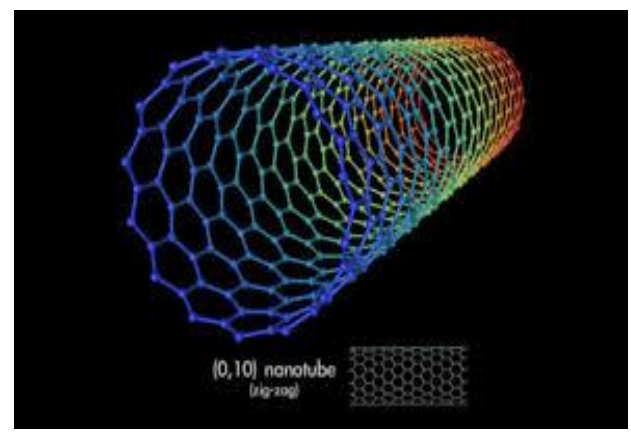

Carbon Nano tubes

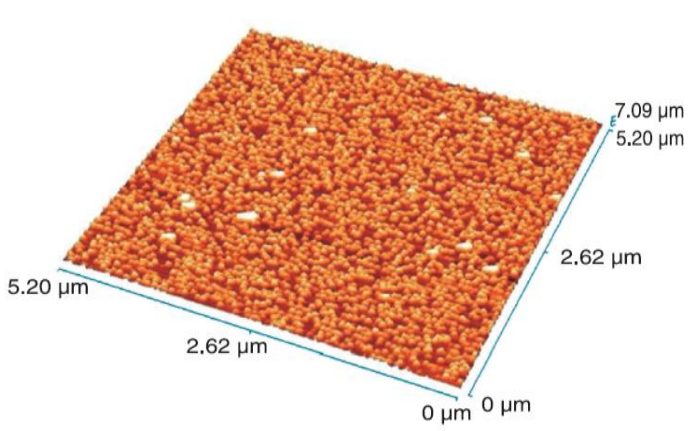

Nitrogen loading in the sheet of Zeolite 


\section{Nutritional value}

Nano fertilizers provide more surface area and more availability of nutrient to the crop plant which help to increase these quality parameters of the plant (such as protein, oil content, sugar content) by enhancing the rate of reaction or synthesis process in the plant system. Application of zinc and iron on the plant increase total carbohydrate, starch, IAA, chlorophyll and protein content in the grain [15]. Nano-Fe2O3 increase photosynthesis and growth of the peanut plant [16].

\section{Health}

Some nutrient also responsible disease resistance to the plant and due tothe more availability of nano nutrient to the plant it prevent from disease, nutrient deficiency and other biotic and abiotic stress which indicate that nano fertilizers enhance overall health of the plant. $\mathrm{ZnO}$ nano-particles also helpful to plant under stress conditions [17]. Aqueous solutions of $\mathrm{Ag}+$ and $\mathrm{Au}+$ drastically reduced the body weight of $P$. ricini larvae [18].

\section{Advantages of nano fertilizers over traditional fertilizers}

Nano fertilizers are advantageous over conventional fertilizers as they increase soil fertility yield and quality parameters of the crop, they are nontoxic and less harmful to environment and humans, they minimize cost and maximize profit. Nano particles increase nutrients use efficiency and minimizing the costs of environment protection [19].

Improvement in the nutritional content of crops and the quality of the taste. Optimum use of iron and increase protein content in the grain of the wheat [20]. Enhance plants growth by resisting diseases and improving stability of the plants by anti-bending and deeper rooting of crops. [8] also suggested that balanced fertilization to the crop plant may be achieved through nanotechnology.

\section{Seeds germination and growth parameters of the plant}

Several researches reported that nano fertilizers significantly influenced the seed germination and seedling growth which revealed the effect of nano fertilizers on seed and seed vigor. Nano fertilizers can easily penetrate into the seed and increase availability of nutrient to the growing seedling which result healthy and more shoot length and root length but if concentration is more than the optimum it may show inhibitory effects on the germination and seedling growth of the plant. The toxicity of $\mathrm{ZnO}$ nano-aprticles on the root growth of garlic (Allium sativum L.) [21]. Nano particles have both positive and negative effects on the plant [22]. Nano $\mathrm{ZnO}$ recorded higher peanut seeds germination percent and root growth compare to bulk zinc sulphate [23]. Similarly positive effective of nano-scale $\mathrm{SiO} 2$ and $\mathrm{TiO} 2$ on germination was reported in soya bean [16]. Reported higher seed germination, shoot length, root length under nano fertilizers treatment over control or without nano fertilizer treated seeds. Nano fertilizers increase availability of nutrient to the growing plant which increase chlorophyll formation, photosynthesis rate, dry matter production and result improve overall growth of the plant [24-27]. Reported similar result that nano$\mathrm{TiO} 2$ treated seed produced plant recorded more dry weight, higher photosynthetic rate, chlorophyll-a formation compared to the control [28]. Which indicate that nano fertilizers significantly improve seed germination and overall growth of the plant.

\section{Yield and yield parameters}

Nano fertilizers enhance the seed germination, vigor, growth parameters (plant 
height, leaf area, leaf area index number of leaves per plant) dry matter production, chlorophyll production, rate of the photosynthesis which result more production and translocation of photosynthets to different parts of the plant. [5] reported similar result that nano-TiO2 treated seed produced plant recorded more dry weight, higher photosynthetic rate, chlorophyll-a formation compared to the control. This improve translocation of photosynthets from source (leaves) to sink (economic part of the plant it may be grain, tuber, bulb, stem, fibre and leaves.) which result in more yield and quality parameters from nano-fetilizers treated plants compare to without nano fertilizers treated plants or traditional fertilizers treated plants. [29-31] reported similar result and nano hydroxyl appetite (nHA) application produced $5.9 \mathrm{~g}$ soybean seeds per plant, compared to $4.9 \mathrm{~g}$ per plant under regular $\mathrm{P}$ treatment, and merely 1.1 and $0.6 \mathrm{~g}$ soybean per plant respectively for the controls without $P$ application [29]. This is the first report on synthesis and application of nHA as nano $\mathrm{P}$ fertilizer for increasing soybean yields. The estimated yield increase by nano-K fertilizer at $20 \mathrm{~kg} \mathrm{~K} 2 \mathrm{O} / \mathrm{ha}$ over MOP at the same level is around $8 \%$ and no significant difference between $20 \mathrm{~kg} \mathrm{~K} 2 \mathrm{O} / \mathrm{ha}$ and $30 \mathrm{Kg} \mathrm{K} 2 \mathrm{O} / \mathrm{ha}$ in the form of nano-K [31]. Accordingly, improvement of grain yield with the application of nano-K fertilizer is highly correlated with the increase in seeds/panicles. $[20,32]$ also reported higher value of yield parameters under nano fertilizers treated plants compare to bulk nutrient sources. Iron content was more in the plant under nano iron treated plant than control [22].

\section{Controlled release of nano-fertilizers and nano-complexes}

Nanotech materials are being developed for slow release and efficient dosages of fertilizers for plant [33]. Nano sizing, in theory, should make fertilizer nutrients more available to nanoscale plant pores and therefore result in efficient nutrient use. Indiscriminate use of chemical fertilizers might cause some unfavourable effects such as soil and water pollution. Nano encapsulated agrochemicals should be designed in such a way that they possess all indispensable properties such as effective concentration(with high solubility, stability and effectiveness), time controlled release in response to certain stimuli, enhanced targeted activity and less Eco toxicity with harmless and effortless mode of delivery thus avoiding repetitive application [34].

Slow-release fertilizers are excellent alternatives to soluble fertilizers as nutrients are released at a slower rate throughout the crop growth; plants are able to take up most of the nutrients without waste by leaching. Slow release of nutrients in the environments could be achieved by using zeolites. Zeolites are a group of naturally occurring minerals having a honeycomb-like layered crystal structure and their network of interconnected tunnels and cages can be laden with nitrogen and potassium along with other slowly dissolving ingredients containing phosphorous, calcium and a complete suite of minor and trace nutrients. Fertilizer particles can be coated with nano membranes that facilitate slow and steady release of nutrients e.g., patented nano composite containing $\mathrm{N}$, $\mathrm{P}, \mathrm{K}$, micronutrients, mannose and amino acids that enhanced the uptake and utilization of nutrients by grain crops has been reported [35].

Carbon nanotubes (CNT) are allotropes of carbon with cylindrical shape and can be utilized to use CNT as vehicle to deliver desired molecules either nutrient or biocides into the seeds during germination. Similarly, triazophos can also be effectively protected from hydrolysis in acidic and neutral media 
by including it ina nano-emulsion [36]. Application of titanium dioxide (TiO2) on food crops has been reported to promote plant growth, increase the photosynthetic rate, reduce disease severity and enhance yield by $30 \%$. The application of $\mathrm{TiO} 2$ has been found to show excellent efficacy in cereal like maize by reducing the effect of Curvularia leaf spot and bacterial leaf blight disease incidence and severity. They also reported that application of $\mathrm{TiO}_{2}$ significantly reduced the incidence of rice blast and tomato spray mold with a correspondent $20 \%$ increase in grain weight due to the growth promoting effect of $\mathrm{TiO}_{2}$ nano-particles [37]. A combination of titanium dioxide, aluminium and silica was reported to be effective in controlling downy and powdery mildew of grapes, possibly through direct action on the hyphae, interference with recognition of plant surface and stimulation of plant physiological defences (Table 1-3).

\section{Need to study}

Research is underway to develop nanocomposite to supply all the required essential nutrients in suitable proportion through smart delivery system which may help in balance supply of nutrient to the crop, there is need to study about nano nutrient delivery in the plant systems, assess the impact of nano fertilizers on soil and soil beneficial microorganism, fate of nano fertilizers in soil and plant have to be studied, need to optimizes concentration and doses of nano fertilizers for different crop and site specific management of nano fertilizers in precision agriculture these are several issues need to standardise to achieve better result from nano-fertiliers in crop production.

Application of different nano-fertilizers have greater role in enhancing crop production this will reduce the cost of fertilizer for crop production and also minimize the pollution hazard. The application of nano-fertilizers in agriculture should have a greater concern to society. Fertilizer nutrient use efficiency in crop production can be enhanced with effective use of nano-fertilizers. Nano fertilizers improve crop growth and yield up to optimum applied doses and concentration but they also have inhibitory effect on crop plant if concentration is more than the optimum which result reduces growth and yield of the crop.

\section{References}

1. Braun H. and Roy R. N. (1983) Proc. Symp. Efficient use of fertilizers in agriculture development in Plant and Soil Science, 10, 251-270.

2. Brunnert I., Wick P., Manserp., Spohnp., Grass R. N., Limbach L. K., Bruinink A. and Stark W. J. (2006) Environmental Science \& Technology, 40, 4374-4381.

3. Chinnamuthu C.R. and Boopati, P.M. (2009) Nanotechnology and agroecosystem. Madras Agric. J. 96:17-31.

4. Chinnamuttu C. R. and Kokiladevi E. (2007) Weed management through nanoherbicides. In: Application of nanotechnology in agriculture.

5. Farajzadeh Memari Tabrizi E., Yarnia M., Khorshidi M. B. and Ahmadzadeh V. (2009) J. Food Agr. Env., 7(2), 611-615.

6. Ghaly A. E. (2009) American J. Biochem. Biotechnol, 5, 210-220.

7. Gutierrez, F.J., Mussons, M.L., Gaton, P and Rojo R. (2011) Nanotechnology and Food Industry. Scientific, Health and Social Aspects of the Food Industry, In Tech, Croatia Book Chapter

8. Hamid R.B. (2012) Arpn J. of Agri. and Biological Sci., 7 (4), 233-237.

9. Hediat M.H. and Salama (2012) International Research Journal of Biotechnology, 3, 190-197.

10. Joseph T. and Morrisson M. (2006) Eur. Nanotechnol. Gateway.

11. Kannan N., Rangaraj S., Gopalu K., Rathinam Y. and Venkatachalam R. (2012) Curr. Nanosci., 8, 902-908. 
12. Lin D. and Xing B. (2007) Environ. Pollut., 150, 243-250

13. Liscano J. F., Wilson C. E., Norman R. J. and Slaton N. A. (2000) AAES Res Bulletin, 963, 1-31.

14. Liu X.M., Zhang F.D., Zhang S.Q., He X.S., Fang R., Feng Z. and Wang Y. (2005) Plant Nutr. Fert. Sci., 11, 14-18.

15. Mahajan P., Shailesh, K., Dhoke R. K. and Anand K. (2013) Nanotechnol., 3, 40524081.

16. Mahmoodzadeh, H., Nabavi, M., Kashefi, H. 2013. Effect of nanoscale titanium dioxide particles on the germination and growth of canola (Brassica napus). $J$ Ornam Hortic Plants. 3:25-32.

17. Naderi M. R. and Abedi A. (2012) J. Nanotech., 11(1), 18-26.

18. Nadi E., Aynehband A. and Mojaddam M., (2013) Int. J. Biosci., 3, 267-272.

19. Nair, R., Varghese, S.H., Nair, B.G., Maekawa, T., Yoshida, Y. and Kumar, D. S. (2010) Nanoparticulate material delivery to plants. Plant Sci. 179:154-163.

20. Nanotechnology in Agriculture, Scope and Current Relevance (2013) National Academy of Agricultural Sciences, New Delhi.

21. Nel A., Xia T., Madlerl and Li N. (2006) Science, 311, 622-627.

22. Pijls L., Ashwell M. and Lambert J. (2009) Food Chem., 113, 748-753.

23. Prasad T.N.V.K.V., Sudhakar P., Sreenivasulu Y., Latha P., Munaswamy V., Raja Reddy K., Sreeprasad T.S., Sajanlal P.R. and Pradeep T. (2012) J. of plant nutrition., 35, 905927.

24. Quasem J. M., Mazahreh A. S. and Abualruz K. (2009) American J. Applied Sci., 6, 888896.
25. Rajaie M. and Ziaeyan A. H. (2009) Int. J. Plant Product, 3(3), 35-440.

26. Rattan L. and Ruiqiang Liu. (2014) Scientific Reports, 4, 5686.

27. Sahayaraj K. Madasamy M. and Anbu R. A. (2014) J. Biopest., 9 (1), 63-72.

28. Silva M. S., Cocenza D. S., Grillo R., Melo N. F. S., Tonello P. S., Oliveira L. C., Cassimiro D. L., Rosa A. H. and Fraceto L. F., (2011) J. Hazardous Materials, 190(13), 366-374.

29. Singh, S. (2012) Achieving Second Green Revolution through Nanotechnology in India. Agric. Situations India. 545-572.

30. Sirisena D. N., Dissanayake D. M. N., SomaweeraK. A. T. N., Karunaratne V. and Kottegoda N., (2013) Annals of SriLanka Department of Agric., 15, 257-262.

31. Suriyaprabha R., Karunakaran G., Yuvakkumar R., Rajendran V. and Kannan N. (2012) J. Current Nanosci., 8, 902-908.

32. Talgar S., Jianxiu G. U., Changshan X. U., Zhikun Y., Qing Z., Yuxue L. and Yichun L. (2011) Nanotoxicology, 1-8.

33. Tarafdar J. C., Agarwal A., Raliya R., Kumar P., Burman U. and Kaul R. K. (2012b) Advanced Science, Engineering and Medicine, 4, 1-5.

34. Tarafdar J. C., Raliya R. and Tathore I. (2012a) Journal of Bionanoscience, 6, 8489.

35. Tarafdar J. C., Raliya R. and Tathore I. (2012a) Journal of Bionanoscience, 6, 8489.

36. Tarafdar J. C., Xiang Y., Wang W. N., Dong Q. and Biswas P. (2012c) Applied Biological Research, 14, 138-144.

37. Zheng L., Hong F., Lu S. and Liu C. (2005) Biol. Trace Elem. Res. 104, 83-91.

\section{How to cite this article:}

Qureshi, A., D.K. Singh and Dwivedi, S. 2018. Nano-fertilizers: A Novel Way for Enhancing Nutrient Use Efficiency and Crop Productivity. Int.J.Curr.Microbiol.App.Sci. 7(02): 33253335. doi: https://doi.org/10.20546/ijcmas.2018.702.398 